\title{
Synthesis and Characterization of Novel Bio-Chiral Dopants Obtained from Bio-Betulin Produced by a Fermentation Process
}

\author{
Veridiana G. Guimarães ${ }^{1}$, Anastasiia Svanidze ${ }^{1}$, Tianyi Guo ${ }^{1}$, Pawan Nepal ${ }^{2}$, Robert J. Twieg ${ }^{2}{ }^{\circledR}$, \\ Peter Palffy-Muhoray ${ }^{1}$ and Hiroshi Yokoyama ${ }^{1, *}$ \\ 1 Advanced Materials and Liquid Crystal Institute, Kent State University, Kent, OH 44242, USA; \\ veridianagguimaraes@gmail.com (V.G.G.); asvanidz@kent.edu (A.S.); tguo2@kent.edu (T.G.); \\ mpalffy@kent.edu (P.P.-M.) \\ 2 Department of Chemistry and Biochemistry, Kent State University, Kent, OH 44242, USA; \\ pnepal@kent.edu (P.N.); rtwieg@kent.edu (R.J.T.) \\ * Correspondence: hyokoyam@kent.edu
}

check for updates

Citation: Guimarães, V.G.; Svanidze,

A.; Guo, T.; Nepal, P.; Twieg, R.J.;

Palffy-Muhoray, P.; Yokoyama, H.

Synthesis and Characterization of

Novel Bio-Chiral Dopants Obtained from Bio-Betulin Produced by a Fermentation Process. Crystals 2021 11, 785. https://doi.org/10.3390/ cryst 11070785

Academic Editor: Charles Rosenblatt

Received: 27 May 2021

Accepted: 1 July 2021

Published: 6 July 2021

Publisher's Note: MDPI stays neutral with regard to jurisdictional claims in published maps and institutional affiliations.

Copyright: (c) 2021 by the authors. Licensee MDPI, Basel, Switzerland. This article is an open access article distributed under the terms and conditions of the Creative Commons Attribution (CC BY) license (https:// creativecommons.org/licenses/by/ $4.0 /)$.

\begin{abstract}
Cholesteric liquid crystals are frequently produced by the addition of chiral dopants to achiral nematic hosts. We report here the synthesis and performance of chiral dopants obtained from bio-betulin produced by a fermentation process. An important aspect of this work is to point out that the fermentation process used to obtain the starting materials is much easier and cheaper when carried out in large volumes than isolating it from the natural product. The performance of the dopants obtained from bio-betulin is indistinguishable from those obtained from commercially available synthetic betulin.
\end{abstract}

Keywords: cholesteric; twist agent; betulin

\section{Introduction}

Cholesteric (chiral nematic) liquid crystal materials are widely distributed in nature [1] The first liquid crystals were discovered accidentally and were simple esters derived from naturally occurring cholesterol [2]. Natural cholesterol (3ß-cholest-5-en-3-ol) has two functional groups, a single secondary $\beta$ alcohol at $C_{3}$ and an alkene between $C_{5}$ and $\mathrm{C}_{6}$. Cholesterol itself is not intrinsically liquid crystalline (K $148 \mathrm{I}$ ); however, many ester derivatives of cholesterol have been synthesized and are often mesogenic. The simple benzoate ester originally studied by Reinitzer is an example (K $\left.145 \mathrm{~N}^{*} 178 \mathrm{I}\right)$ [2]. Here, $\mathrm{N}^{*}$ is the symbol for the chiral nematic phase (and often called a cholesteric phase given the origin of the discovery of this phase in cholesterol derivatives).

Since their initial discovery, numerous other intrinsically chiral substances, some natural, some semi-synthetic, and some totally synthetic in origin, have been identified as cholesteric liquid crystal (CLC) materials [3]. In addition to intrinsically chiral substances, which possess a cholesteric phase, simple nonchiral nematic host materials can be mixed with chiral dopants to produce compositions with cholesteric phases. Just as is the case with the origin of the host molecules, the dopants themselves can be natural, semi-synthetic, or totally synthetic in origin. An example of the use of a natural twist agent is the case of the monoterpene D-limonene, which is derived from citrus [4]. Examples of semisynthetic twist agents are the ester derivatives of the dianhydrohexitols isosorbide and isomannide, which themselves can be derived from glucose and sucrose, respectively [5]. The resulting physical properties of a cholesteric mixture are dependent on the specific identities of the specific host and dopant as well as their ratio in the mixture.

Along with the enormous structural diversity of cholesteric materials, there are also a wide range of associated physical phenomena and related applications [3]. Cholesteric materials with improved properties are being actively pursued for many applications. Amongst them, electro-optically responsive cholesteric materials have found applications 
as tunable photonic bandgap elements [6]. In order to produce practical and reliable devices, materials are sought with the appropriate physical properties permitting a fast response and high stability.

This manuscript describes the utilization of the chiral precursor betulin, which can be structurally modified to produce chiral dopants suitable for application in reconfigurable photonic bandgap materials. The betulin used in this study came from both natural sources (referred to here simply as betulin) and fermentation sources (referred to here as biobetulin). Betulin was anticipated to be a suitable precursor, which, similar to cholesterol, could be esterified to produce chiral dopants that could be loaded into nematic hosts in sufficient quantity to produce the cholesteric bandgap structures, which operated in the visible and infrared range. The betulin derivatives described here are benzoate-derived diesters where the two ester groups (installed at the two alcohol groups of Lup-20(29)ene-3 $\beta, 28$-diol) are identical. The guest-host compositions were stable in that they did not undergo phase changes outside the desired cholesteric phase at useful loading levels. Additionally, the compositions were robust so as to have reproducible physical and optical responses to applied stimuli such as electric and magnetic fields and temperature.

Betulin (Lup-20(29)-ene-3 $\beta, 28-\mathrm{diol}$ ) is a pentacyclic lupane triterpenoid natural product that was first isolated from birch bark. Betulin has three functional groups, which include a secondary $\beta$-alcohol at $C_{3}$, a primary (but neopentyl type) alcohol at $C_{28}$, and an alkene between $C_{20}$ and $C_{29}$. Both betulin and betulinic acid (in which there is a $C_{28}$ carboxylic acid instead of an alcohol as in betulin) have been widely examined as substrates for preparation of derivatives with biological activity [7]. Betulin derived from natural sources must undergo a multistep purification process in order to separate it from other plant constituents [8,9] prior to its use in many applications. Betulin itself or its simple ester derivatives, to our knowledge, have not been previously examined as twist agents. However, betulin derivatives such as betulinic aldehyde [10] and allobetulin or allobetulone [11,12] have been examined in different liquid crystal-related applications.

Here, we describe the chiral dopants CD29 (betulin bis- $p$-toluyl diester) and CD46 (betulin bis- $p$ - $n$-butylbenzoyl diester), each of which were synthesized using similar synthetic methodology from commercially available betulin derived from natural sources. In addition, we also describe the chiral dopants bio-CD29 (bio-betulin bis- $p$-toluyl diester) and bio-CD46 (bio-betulin bis- $p$ - $n$-butylbenzoyl diester), each of which were synthesized using similar synthetic methodology from bio-betulin itself prepared by fermentation. Fermentation-derived bio-betulin does not require as complicated a purification regimen as is required for betulin obtained from natural sources. Fermentation in volume is easier and cheaper than isolation from the natural product. The CD29 and CD46 are a small subset of a large group of derivatives we have prepared from commercial betulin and have been examined as chiral dopants. After screening of relevant physical properties, the CD29 and CD46 were selected from this large group for further study based on their favorable physical properties. These two derivatives proved to be useful, and their synthesis was then repeated using bio-betulin to give bio-CD29 and bio-CD46. All the dopants obtained from the commercial natural betulin and fermentation-derived bio-betulin were characterized and compared by a combination of spectroscopic techniques (IR, ${ }^{1} \mathrm{HNMR}$, ${ }^{13} \mathrm{CNMR}$ ) and other analytical methods (HPLC and melting point determination). These examinations confirmed that the respective dopants obtained from the commercial and fermentation-derived betulin sources were identical.

The dopants CD29 and CD46 were synthesized by a slight modification of reported literature procedures (Figure 1) $[13,14]$. Both of the alcohol groups in betulin are sterically hindered, and the esterifications were run under more aggressive conditions (heating and the use of the hypernucleophilic base DMAP) than otherwise usually employed for esterification. The CD29 was obtained by the esterification of betulin with toluyl chloride in the presence of pyridine and 4-dimethylaminopyridine (DMAP). The CD46 was synthesized by the reaction of betulin with $p$ - $n$-butylbenzoyl chloride in presence of pyridine and DMAP (Figure 1). The respective pure final diester products were obtained 
after both column chromatography and recrystallization. Unlike many of the cholesterol monobenzoates, the betulin bisbenzoates CD29 and CD46 have no intrinsic mesogenic properties. Synthetic details and chemical spectroscopic characterization for the dopants are described below. Further discussion and data for purity analyses are found in the Supplementary Information.

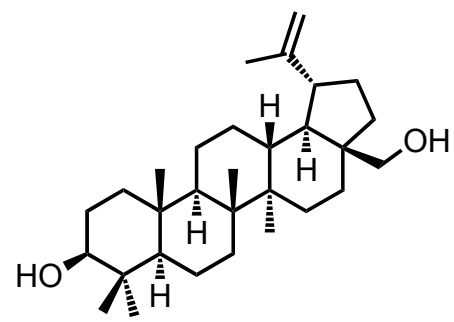

betulin OR bio-betulin
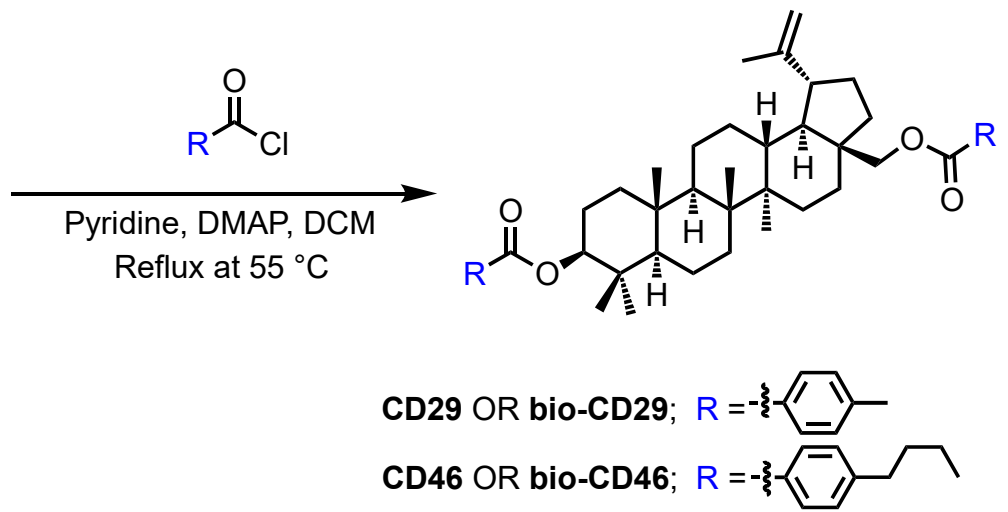

Figure 1. Synthesis of the chiral dopants CD29 and CD46 from commercially available natural betulin and the synthesis of the chiral dopants bio-CD29 and bio-CD46 from bio-betulin (which itself was prepared by fermentation).

\section{Physical Characterization}

The induced cholesteric mesophases are produced by the addition of small quantities of a chiral compound as a dopant into an achiral nematic liquid crystal host. The chirality from the chiral dopant compound is transmitted to the whole system, forming a helical structure with the assembly of liquid crystal molecules perpendicular to the helix axis, being either left- or right-handed depending on the chiral interactions. The resulting structure is characterized by the magnitude of helix pitch $P$, which is determined by the chemical structure of the molecules forming the cholesteric, both nematic host and chiral compound, as well as their ratio in the mixture. The amount of chiral dopant needed to reach a cholesteric phase with a certain pitch is expressed in the helical twisting power (HTP, $\beta$ ). The periodicity of the structure generates a selective reflection band, where incident light of the same handedness as the structure is totally reflected. The average wavelength of the reflected light is based on the average refractive index and helix pitch, $\bar{\lambda}=\bar{n} P[15,16]$. It is due to this optical property that cholesteric liquid crystals are functional materials that have many applications such as reflective displays [17-19], color filters [20], sensors [21,22], lasers [23-25], and temperature indicators [26,27].

\section{Experimental}

3.1. Materials

All the solvents used were obtained from commercial sources and were used without further purification. Unless stated, all solvents used for the reactions were high quality anhydrous solvents. The commercial betulin $98 \%$ (presumed to be derived from processing of natural material) was purchased from Ark Pharm Inc., Arlington Heights, IL, USA. The fermentation-derived bio-betulin was obtained from Zymergen (Emeryville, CA, USA). Pyridine was obtained from Alfa Aesar, $p$ - $n$-butylbenzoyl chloride was obtained from Fluorochem Inc. (Glossop, UK), DMAP was obtained from Oakwood Products, Inc. (Estill, SC, USA), and the $p$-toluoyl chloride was obtained from Acros Organics. Product (Geel, Belgium) purifications were done by column chromatography using silica gel (60-120 mesh) and/or recrystallizations from analytical grade solvents.

The E7 liquid crystal mixture and chiral dopant CB15 were purchased from Merck Group (Darmstadt, Germany). Polyimide PI2555 from HD MicroSystems (Sayreville, NJ, USA), and poly(vinyl alcohol) (PVA) 98\% from Sigma-Aldrich (Steinheim am Albuch, Germany) were used for planar alignment. 


\subsection{Characterization Equipment}

Polarized optical microscopy (POM) was done to determine the phase behavior using a Nikon ECLIPSE E600 Microscope (Nikon Inc., Melvile, NY, USA) and SPOT ${ }^{\mathrm{TM}}$ idea COMS (SPOT Imaging, Sterling Heights, MI, USA)and a Mettler Toledo FP90 central processor with FP82HT hot stage (Hightstown, NJ, USA). IR analysis was accomplished by using a Bruker Vector 33 FTIR spectrometer (Bruker Optics Inc., Billerica, MA, USA). The data obtained were processed and plotted using OPUS software (ver. 6.5, Bruker Optics Inc., Billerica, MA, USA). A Bruker 400 NMR (Bruker Optics Inc., Billerica, MA, USA) was used for NMR data acquisition (Frequency: $400 \mathrm{MHz}$ for ${ }^{1} \mathrm{H}-\mathrm{NMR}$; $100 \mathrm{MHz}$ for ${ }^{13} \mathrm{C}$ NMR), and the plots were generated by TOPSPIN 2 software (ver. 2.1, Bruker Optics Inc., Billerica, MA, USA). Product purity and reaction progress was monitored by thin layer chromatography (TLC). The developed TLC plates were visualized under UV light. The HPLC analysis of the products were carried out on an Agilent 1100 Series HPLC instrument (Agilent Technologies Waldbronn, Germany).

For physical characterization meanings $\mathrm{POM}$ of the mixtures were observed with a polarizing microscope (NIKON-OPTIPHOT-POL, Nippon Kogaku K.K., Tokyo, Japan) equipped with digital camera (AmScope MT900, Irvine, CA, US). A stage micrometer of $0.01 \mathrm{~mm}$ (AmScope, Irvine, CA, US) was used to calibrate the length of a pixel from the image according to the chosen objective lens. The spherical lenses utilized in the spherical wedge cell, KPX561 N-BK7, were from Newport Corporation (Franklin, MA, USA). Transmission spectra were collected with Ocean Optics HR4000 spectrometer (Ocean Optics Inc., Winter Park, FL, USA). For temperature control, hot stage Instec HCS302 was controlled by Instec mK 2000 (INSTEC Inc., Boulder, CO, USA). The source used for the UV exposure stability evaluation was QUV accelerated weathering tester with UVA-340 lamps with close resemblance to the solar spectrum for wavelengths below 350nm (Q-Lab Corporation, Westlake, OH, USA). For the thermal cycling test, the Thermotron 8200 model S-1.2-8200 (Thermotron Industries, Holland, MI, USA) was utilized. Both stability tests were realized with access provided by AlphaMicron, Inc. (Kent, OH, USA).

\subsection{Synthesis and Chemical Characterization of Chiral Dopants}

\subsubsection{Preparation of Bio-CD29 (Using Fermentation-Derived Bio-Betulin)}

In a $200 \mathrm{~mL}$ recovery flask with stir bar and reflux condenser was placed bio-betulin (3.740 gm, $8.4 \mathrm{mmol})$, dry dichloromethane $(25 \mathrm{~mL}), p$-toluoyl chloride $(5.256 \mathrm{gm}, 34.0 \mathrm{mmol})$, pyridine $(25 \mathrm{~mL})$, and 4-dimethylaminopyridine $(3.050 \mathrm{gm}, 25.0 \mathrm{mmol})$. The mixture was protected under a nitrogen atmosphere and refluxed at $55^{\circ} \mathrm{C}$ overnight. After this time, TLC indicated the complete consumption of the starting material and formation of a new less polar product. The flask was cooled to room temperature, and cold water $(50 \mathrm{~mL})$ was added. The product was extracted with ethyl acetate $(3 \times 25 \mathrm{~mL})$, washed with brine, and dried over anhydrous $\mathrm{MgSO}_{4}$. Solvent was evaporated, and the liquid obtained was absorbed on $30 \mathrm{cc}$ of silica gel with $50 \mathrm{~mL}$ of ethyl acetate. The absorbed material was placed at the top of the silica gel column made up with hexanes to elute (solvent: ethyl acetate: hexanes 1:9). Concentration of the fractions provided a solid product, which was recrystallized from 1-PrOH (yield $=4.495 \mathrm{gm}, 79 \%$ ).

Melting Point: $207-209^{\circ} \mathrm{C}$.

${ }^{1} \mathrm{HNMR}\left(\mathrm{CDCl}_{3}, 400 \mathrm{MHz}\right): \delta=7.92-7.95(\mathrm{~m}, 4 \mathrm{H}), 7.22-7.26(\mathrm{~m}, 4 \mathrm{H}), 4.68-4.73(\mathrm{~m}$, $2 \mathrm{H}), 4.61-4.62(\mathrm{~m}, 1 \mathrm{H}), 4.51(\mathrm{~d}, \mathrm{~J}=10.9 \mathrm{~Hz}, 1 \mathrm{H}), 4.07(\mathrm{~d}, \mathrm{~J}=11.0 \mathrm{~Hz}, 1 \mathrm{H}), 2.50-57(\mathrm{~m}, 1 \mathrm{H})$, $2.41(\mathrm{~s}, 3 \mathrm{H}), 2.41(\mathrm{~s}, 3 \mathrm{H}), 1.71(\mathrm{~s}, 3 \mathrm{H}), 1.08(\mathrm{~s}, 3 \mathrm{H}), 1.02(\mathrm{~s}, 3 \mathrm{H}), 0.99(\mathrm{~s}, 3 \mathrm{H}), 0.91(\mathrm{~s}, 3 \mathrm{H}), 0.90$ $(\mathrm{s}, 3 \mathrm{H})$.

${ }^{13} \mathrm{CNMR}\left(\mathrm{CDCl}_{3}, 100 \mathrm{MHz}\right): \delta=167.1,166.4,150.2,143.5,143.3,129.6,129.0,128.3$, 127.7, 109.9, 81.3, 63.1, 55.5, 50.3, 48.9, 47.8, 46.7, 42.8, 40.9, 38.4, 38.2, 37.7, 37.1, 34.7, 34.1, $30.0,29.6,28.1,27.1,25.2,23.8,21.7,21.7,20.8,19.2,18.2,16.8,16.2,16.1,14.8$.

IR $\left(\mathrm{Cm}^{-1}\right): 2948,2873,1712,1612,1452,1270,1177,1120,969,838,751$. 


\subsubsection{Preparation of CD29 (Using Commercial Natural Betulin)}

In a $2000 \mathrm{~mL}$ recovery flask with stir bar was placed betulin $(44.300 \mathrm{gm}, 100.0 \mathrm{mmol})$, dry dichloromethane $(450 \mathrm{~mL}), p$-toluoyl chloride $(61.800 \mathrm{gm}, 400.0 \mathrm{mmol})$, pyridine $(250 \mathrm{~mL})$, and 4-dimethylaminopyridine $(19.874 \mathrm{gm}, 162.6 \mathrm{mmol})$. The mixture was protected under a nitrogen atmosphere and refluxed at $55^{\circ} \mathrm{C}$ for five hours. After this time, TLC indicated the complete consumption of the starting material and formation of two new less polar products. The mixture was left stirring at $55^{\circ} \mathrm{C}$ overnight and monitored by TLC, which indicated the complete consumption of the starting material to give a single less polar product. Then, cold water $(200 \mathrm{~mL})$ and $10 \% \mathrm{HCl}(200 \mathrm{~mL})$ were added dropwise with stirring. The product was extracted with ethyl acetate $(3 \times 250 \mathrm{~mL})$, washed with water, and dried over anhydrous $\mathrm{MgSO}_{4}$. Solvent was evaporated, and the liquid obtained was absorbed on $300 \mathrm{cc}$ of silica gel with $500 \mathrm{~mL}$ of ethyl acetate. The absorbed material was placed at the top of the silica gel column made up with ethyl acetate: hexane 1:9 to elute (solvent: ethyl acetate: hexanes 1:9). Concentration of the fractions provided a solid product, which was recrystallized from 1-PrOH (yield $=57.682 \mathrm{gm}, 85 \%$ ).

Melting Point: $207-209^{\circ} \mathrm{C}$.

${ }^{1} \mathrm{HNMR}\left(\mathrm{CDCl}_{3}, 400 \mathrm{MHz}\right): \delta=7.92-7.95(\mathrm{~m}, 4 \mathrm{H}), 7.22-7.26(\mathrm{~m}, 4 \mathrm{H}), 4.68-4.73(\mathrm{~m}$, $2 \mathrm{H}), 4.61-4.62(\mathrm{~m}, 1 \mathrm{H}), 4.51(\mathrm{~d}, \mathrm{~J}=10.4 \mathrm{~Hz}, 1 \mathrm{H}), 4.07(\mathrm{~d}, \mathrm{~J}=11.0 \mathrm{~Hz}, 1 \mathrm{H}), 2.50-2.57(\mathrm{~m}, 1 \mathrm{H})$, $2.41(\mathrm{~s}, 3 \mathrm{H}), 2.40(\mathrm{~s}, 3 \mathrm{H}), 1.71(\mathrm{~s}, 3 \mathrm{H}), 1.08(\mathrm{~s}, 3 \mathrm{H}), 1.02(\mathrm{~s}, 3 \mathrm{H}), 0.99(\mathrm{~s}, 3 \mathrm{H}), 0.91(\mathrm{~s}, 3 \mathrm{H}), 0.90$ $(\mathrm{s}, 3 \mathrm{H})$.

${ }^{13} \mathrm{CNMR}\left(\mathrm{CDCl}_{3}, 100 \mathrm{MHz}\right): \delta 167.1,166.4,150.2,143.5,143.3,129.6,129.0,128.3,127.8$, $109.9,81.3,63.1,55.5,50.3,48.9,47.8,46.7,42.8,40.9,38.4,38.2,37.7,37.1,34.7,34.1,30.0$, 29.7, 28.1, 27.2, 25.2, 23.8, 22.7, 21.7, 21.6, 20.9, 19.2, 18.2, 16.8, 16.2, 16.1, 14.8.

IR $\left(\mathrm{Cm}^{-1}\right): 2947,2872,1713,1612,1453,1269,1177,1105,969,838,751$.

\subsubsection{Preparation of Bio-CD46 (Using Fermentation-Derived Bio-Betulin)}

In a $200 \mathrm{~mL}$ recovery flask with stir bar was placed bio-betulin $(4.430 \mathrm{gm}, 10.0 \mathrm{mmol})$, dry dichloromethane $(30 \mathrm{~mL}), p$ - $n$-butylbenzoyl chloride $(5.580 \mathrm{gm}, 30.0 \mathrm{mmol})$, pyridine $(30 \mathrm{~mL})$, and 4-dimethylaminopyridine $(3.666 \mathrm{gm}, 30.0 \mathrm{mmol})$. The mixture was protected under nitrogen atmosphere and warmed at $55{ }^{\circ} \mathrm{C}$ overnight. After this time, TLC indicated the complete consumption of the starting material to give single less polar product. Then, cold water $(30 \mathrm{~mL})$ and $10 \% \mathrm{HCl}(50 \mathrm{~mL})$ was added dropwise with stirring. Phases were separated, and the aqueous phase was extracted with ethyl acetate $(3 \times 25 \mathrm{~mL})$. The organic phases were combined, washed with water, and dried over anhydrous $\mathrm{MgSO}_{4}$. Solvent was evaporated, and the liquid obtained was absorbed on $50 \mathrm{cc}$ of silica gel with $50 \mathrm{~mL}$ of ethyl acetate. After concentration to dryness, the absorbed material was placed at the top of the silica gel column made up with hexanes to elute (solvent: ethyl acetate: hexanes 1:20). Concentration of fractions provided a solid product, which was recrystallized from 1- $\mathrm{PrOH} / \mathrm{H}_{2} \mathrm{O}$ (40:1). (yield = $6.523 \mathrm{gm}, 86 \%$ ).

Melting point: $160-162{ }^{\circ} \mathrm{C}$.

${ }^{1} \mathrm{HNMR}\left(\mathrm{CDCl}_{3}, 400 \mathrm{MHz}\right): \delta$ = 7.94-7.97 $(\mathrm{m}, 4 \mathrm{H}), 7.22-7.26(\mathrm{~m}, 4 \mathrm{H}), 4.68-4.73(\mathrm{~m}$, $2 \mathrm{H}), 4.61-4.62(\mathrm{~m}, 1 \mathrm{H}), 4.51(\mathrm{~d}, \mathrm{~J}=10.7 \mathrm{~Hz}, 1 \mathrm{H}), 4.07(\mathrm{~d}, \mathrm{~J}=11.2 \mathrm{~Hz}, 1 \mathrm{H}), 2.64-2.68(\mathrm{~m}, 4 \mathrm{H})$, 2.50-2.57 (m, 1H), $1.71(\mathrm{~s}, 3 \mathrm{H}), 1.08(\mathrm{~s}, 3 \mathrm{H}), 1.02(\mathrm{~s}, 3 \mathrm{H}), 0.99(\mathrm{~s}, 3 \mathrm{H})$.

${ }^{13} \mathrm{CNMR}\left(\mathrm{CDCl}_{3}, 100 \mathrm{MHz}\right): \delta=167.1,166.4,150.2,148.5,148.3,129.6,129.6,128.5$, 128.4, 128.4, 127.9, 109.9, 81.3, 63.1, 55.5, 50.3, 48.9, 47.8, 46.7, 42.8, 40.9, 38.4, 38.2, 37.7, 37.1, $35.7,34.8,34.1,33.3,30.0,29.7,29.7,29.6,28.1,27.1,25.2,23.8,22.3,20.8,19.2,18.2,16.8,16.2$, $16.1,14.8,13.9$.

IR $\left(\mathrm{cm}^{-1}\right):$ 2939, 2872, 1714, 1611, 1463, 1454, 1269, 1175, 1106, 1020, 971.

\subsubsection{Preparation of CD46 (Using Commercial Natural Betulin)}

In a $100 \mathrm{~mL}$ recovery flask with stir bar was placed betulin $(0.443 \mathrm{gm}, 1.0 \mathrm{mmol})$, dry dichloromethane $(10 \mathrm{~mL}), p$ - $n$-butylbenzoyl chloride $(0.558 \mathrm{gm}, 3.0 \mathrm{mmol})$, pyridine $(10 \mathrm{~mL})$, and 4-dimethylaminopyridine $(0.366 \mathrm{gm}, 3.0 \mathrm{mmol})$. The mixture was protected under nitrogen atmosphere and refluxed at $55^{\circ} \mathrm{C}$ for five hours. After this time, TLC 
indicated the formation of two new products. Additional pyridine (3.0 mL), DMAP (0.122 gm, $1.0 \mathrm{mmol})$, and $p$ - $n$-butylbenzoyl chloride $(0.392 \mathrm{gm}, 2.0 \mathrm{mmol})$ was added, and the mixture was left stirring at $55^{\circ} \mathrm{C}$ overnight. After this time, TLC indicated the complete consumption of the starting material to give a single less polar product. Then, cold water $(50 \mathrm{~mL})$ and $10 \% \mathrm{HCl}(5 \mathrm{~mL})$ was added dropwise with stirring. The product was extracted with ethyl acetate $(3 \times 25 \mathrm{~mL})$, washed with water, and dried over anhydrous $\mathrm{MgSO}_{4}$. Solvent was evaporated, and the liquid obtained was absorbed on 20 cc of silica gel with $50 \mathrm{~mL}$ of ethyl acetate. After concentration to dryness, the absorbed material was placed at the top of the silica gel column made up with ethyl acetate: hexane 1:9 to elute (solvent: ethyl acetate: hexanes 1:9). Concentration of the fractions provided a solid product, which was recrystallized from $1-\mathrm{PrOH} / \mathrm{H}_{2} \mathrm{O}$ (yield $=0.410 \mathrm{gm}, 54 \%$ ).

Melting Point: $159-161^{\circ} \mathrm{C}$.

${ }^{1} \mathrm{HNMR}\left(\mathrm{CDCl}_{3}, 400 \mathrm{MHz}\right): \delta=7.93-7.97(\mathrm{~m}, 4 \mathrm{H}), 7.23-7.26(\mathrm{~m}, 4 \mathrm{H}), 4.68-4.72(\mathrm{~m}$, $1 \mathrm{H}), 4.61-4.62(\mathrm{~m}, 1 \mathrm{H}), 4.51(\mathrm{~d}, \mathrm{~J}=10.8 \mathrm{~Hz}, 1 \mathrm{H}), 4.07(\mathrm{~d}, \mathrm{~J}=11.0 \mathrm{~Hz}, 1 \mathrm{H}), 2.63-2.68(\mathrm{~m}, 4 \mathrm{H})$, 2.50-2.57 (m, 1H), $1.72(\mathrm{~s}, 3 \mathrm{H}), 1.08(\mathrm{~s}, 3 \mathrm{H}), 1.02(\mathrm{~s}, 3 \mathrm{H}), 0.99(\mathrm{~s}, 3 \mathrm{H})$.

${ }^{13} \mathrm{CNMR}\left(\mathrm{CDCl}_{3}, 100 \mathrm{MHz}\right): \delta=167.1,166.4,150.2,148.5,148.3,129.6,129.6,128.5$, $128.4,128.4,127.9,109.9,81.3,63.1,55.5,50.3,48.9,47.8,46.7,42.8,40.9,38.4,38.2,37.7,37.1$, $35.7,34.8,34.1,33.3,30.0,29.7,29.7,29.6,28.1,27.1,25.2,23.8,22.3,20.8,19.2,18.2,16.8,16.2$, $16.1,14.8,13.9$.

IR (cm $\left.{ }^{-1}\right): 2951,2926,2868,1714,1610,1456,1269,1176,1105,1019,972$.

\subsection{Mixture of Chiral Dopants and Host Nematic Liquid Crystal}

Synthesized chiral dopants derivatives of commercial betulin CD46 and CD29 and bio-betulin bio-CD46 and bio-CD29 were mixed into a host nematic liquid crystal for the characterization of physical properties. Chiral dopant and liquid crystal, E7 mixture, were weighed in required proportion and placed into a glass vial with a magnetic stirrer. To eliminate spurious history, such as crystallization due to concentration inhomogeneities, we implemented a special protocol for mixture preparation, promoting stability enhancement against phase separation and enabling reliable comparison of mixtures. The protocol has the following steps:

I. Glass vial with mixture was placed on the hotplate, heated above the clearing point (about $90^{\circ} \mathrm{C}$ ), and stirred vigorously for $60 \mathrm{~min}$;

II. Mixture was centrifuged at $6000 \mathrm{rpm}$ for $10 \mathrm{~min}$;

III. Repeat step I for $5 \mathrm{~min}$;

IV. Repeat step II;

V. $\quad$ Repeat step I for $5 \mathrm{~min}$;

VI. Repeat step II.

The nematic-chiral dopant mixtures consisting of the CD29 and bio-CD29 were prepared in the concentrations of 2 wt.\%, 3 wt.\%, 4 wt.\%, 5 wt.\%, and 7 wt., $\%$, while for the CD46 and bio-CD46, we prepared concentrations of 2 wt. $\%, 4$ wt. $\%, 6$ wt. $\%, 8$ wt. $\%$, 10 wt. \%, and 12 wt.\%. Different concentrations of the two dopants were used due to their different solubilities in the nematic LC host. The chiral dopants CD29 and bio-CD29 tend to crystallize for concentrations above $5 \mathrm{wt}$.\% within a few days after mixture preparation. For CD46 and bio-CD46, crystallization occurs above $10 \mathrm{wt.} \%$.

\subsection{Spherical Wedge Cell Preparation}

For pitch measurements, spherical wedge cells consisting of a plane glass substrate and a plano-convex lens have been prepared. To provide planar alignment, the substrate was spin-coated with polyimide PI2555 solution, baked on hotplate at $80{ }^{\circ} \mathrm{C}$ for $5 \mathrm{~min}$, and then oven-baked at $275^{\circ} \mathrm{C}$ for $1 \mathrm{~h}$. Afterwards, for unidirectional alignment, the substrate was rubbed ten to fifteen times with velvet cloth using a rubbing block. For the lens, planar alignment was achieved with PVA coating by dipping the convex side into a solution of $1 \mathrm{wt}$ \% PVA in DI water for $1 \mathrm{~min}$, then, the excess amount of solution was removed by gently shaking off the solution, and the lens was placed on a hot plate at $90^{\circ} \mathrm{C}$ for $3 \mathrm{~min}$ 
with coated side facing up. Since the lens is reusable, PVA was chosen instead of polyimide. After drying, the convex side was rubbed gently ten to fifteen times with a velvet cloth using the rubbing block. The lens radius of the convex side curvature is $R_{l}=51.68 \mathrm{~mm}$.

The spherical wedge cell was assembled by placing a drop of CLC at the center of the plane substrate and on top of it the convex side of lens, having the substrate and lens rubbing directions parallel to each other. An interval of at least 5 min was allowed for forming disclination lines and relaxation to equilibrium.

\section{Results and Discussion}

\subsection{Helical Twisting Power}

To determine the pitch and, subsequently, the HTP of the novel chiral dopants from commercial and bio-derivatives in the chosen host, the Grandjean-Cano wedge method for spherical (plano-convex) lens was carried out. Substrate and lens had parallel easy orientation directions and CLC constrained in between them formed cylindrical disclination walls (concentric circles from top view). Each wall separates regions where an integer number of $P / 2$ is fitted in between substrate and lens. Since the gap thickness increases, the number of half pitches increases by one incrementally from the center to the edge. The free energy cost in this configuration is huge, so disclination lines are induced to reduce the free energy, dividing the wedge cell into regions. The radii $R_{n}$ of the circular disclination lines are related to the helix pitch by:

$$
\frac{R_{n}{ }^{2}}{R_{l}}=P\left(n-\frac{1}{2}\right)
$$

where $n$ is the number of disclination lines indicated from the center.

One can determine the radii of the disclination lines from a POM image. Figure 2 exemplifies the textures acquired for the four chiral dopants mixtures, CD29 and bio-CD29 at $2 \mathrm{wt}$ \% concentration and CD46 and bio-CD46 at $10 \mathrm{wt} . \%$ concentration. Here, color similarity of images highlights the pitch comparability of mixtures. The $R_{n}$ measurements were realized through AmScope software multiple times and are averaged. Linear fitting of $R_{n}^{2} / R_{l}$ vs. $n$ yields a value of the pitch determined by the slope. The ability of chiral molecules to induce a helical structure in an achiral media is known as the helical twisting power $\beta$.

$$
\beta=\frac{1}{P C}
$$

where $C$ is the unitless weight fraction of the chiral dopant (although, throughout the text for convenience, it is referred as wt.\%). After determining the pitch for all mixtures mentioned before, the HTP was calculated from linear fitting of $1 / P$ vs. $C$ with the intercept fixed at the origin. The obtained data for the pitch and HTP of commercial and bio-reachable chiral dopants are presented and compared in Table 1. Low concentration mixtures show higher data discrepancy since small deviations in concentration lead to significant changes in pitch, whereas in other mixtures, the error is less than $2 \%$. The HTP obtained for CD29 and bio-CD29 is $27.0 \mu \mathrm{m}^{-1}$, and for CD46 and bio-CD46, they are $31.1 \mu^{-1}$ and $31.5 \mu \mathrm{m}^{-1}$, respectively. From the results in this table, we conclude that, based on the measured pitches and the HTP values, the effects of the commercial betulin and fermentation produced bio-betulin on induced chirality of the mixtures studied are indistinguishable.

Another main structural characteristic is the handedness of the helix. To date, no means exist to predict which chiral molecular configuration will give a certain helix handedness [19]. Moreover, the handedness of the cholesteric helix may be different for the same chiral dopant in different hosts [28]. To determine the helix handedness, a miscibility test with a well-known commercial chiral dopant can be performed. Here, we used CB15, which is right handed in an E7 nematic host [29]. In order to conduct the test, a mixture of each chiral dopant (CD29, bio-CD29, CD46, and bio-CD46 in E7) was placed in contact with the mixture of known handedness in a cell with planar alignment. The mixing area 
of two cholesteric liquid crystals showed a discontinuous region, pointing to the opposite handedness of the chiral dopants with respect to CB15 for this nematic host. A black line of unwound liquid crystal was observed when the microscope polarizer is along director alignment and bright when the polarizer was at $45^{\circ}$ with director alignment. We can conclude from these observations that these chiral dopants present a left-handed helix in E7.
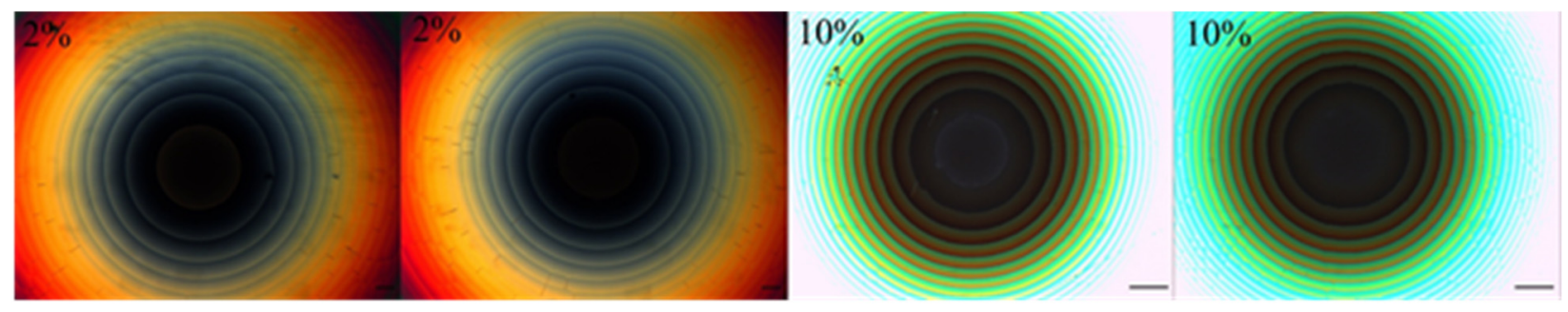

Figure 2. Textures of the Grandjean-Cano spherical wedge cells acquired for the four chiral dopants mixtures, CD29 and bio-CD29 in the $2 \mathrm{wt} . \%$ concentration (left) and CD46 and bio-CD46 in the $10 \mathrm{wt} . \%$ (right). Color similarity quantitatively highlights the pitch comparability between the respective commercial and bio-reachable chiral dopants mixtures.

Table 1. Pitch dependence on concentration of chiral dopants CD29 and CD46 in the commercial and bio-reachable form in E7 nematic host. The HTP of each chiral dopant obtained from the slope of the dependence of reverse pitch vs. concentration are shown in the last line.

\begin{tabular}{|c|c|c|c|c|c|}
\hline$C$ (wt.\%) & $P(\mu \mathrm{m})$ for CD29 & $\begin{array}{l}P(\mu \mathrm{m}) \text { for } \\
\text { bio-CD29 }\end{array}$ & $C$ (wt.\%) & $P(\mu \mathrm{m})$ for CD46 & $\begin{array}{l}P(\mu \mathrm{m}) \text { for } \\
\text { bio-CD46 }\end{array}$ \\
\hline 2 & 1.84 & 1.73 & 2 & 1.64 & 1.72 \\
\hline 3 & 1.30 & 1.25 & 4 & 0.85 & 0.84 \\
\hline 4 & 0.89 & 0.91 & 6 & 0.53 & 0.53 \\
\hline 5 & 0.77 & 0.77 & 8 & 0.40 & 0.39 \\
\hline \multirow[t]{2}{*}{7} & 0.52 & 0.52 & 10 & 0.32 & 0.32 \\
\hline & & & 12 & 0.27 & 0.26 \\
\hline $\operatorname{HTP}\left(\mu \mathrm{m}^{-1}\right)$ & $27.0 \pm 0.1$ & $27.0 \pm 0.4$ & $\operatorname{HTP}\left(\mu \mathrm{m}^{-1}\right)$ & $31.1 \pm 0.2$ & $31.5 \pm 0.2$ \\
\hline
\end{tabular}

\subsection{Reflection Band}

The functionality and the wide range of applications of CLCs as optically active materials are due to the self-assembled helical structure. Because of its periodicity, CLC acts as a 1D photonic bandgap material, which generates a selective reflection band, where incident light of the same handedness as the structure is totally reflected. At normal incidence, the reflection bandwidth $\Delta \lambda$ is given by $\Delta \lambda=\lambda_{\max }-\lambda_{\min }=\left(n_{e}-n_{0}\right) P=\Delta n P$, where $n_{o}$ and $n_{e}$ represent the ordinary and extraordinary refractive indices, respectively. The refractive indices of the host, E7, are $n_{0}=1.5224$ and $n_{e}=1.7394$ at $20^{\circ} \mathrm{C}$ for light with $589 \mathrm{~nm}$ wavelength. Figure 3 presents the bandgap location in the visible range of $12 \mathrm{wt} . \%, 10 \mathrm{wt} . \%, 8 \mathrm{wt} . \%$, and $6 \mathrm{wt.} \%$ concentrations for CD46 and bio-CD46 mixtures. Since the pitch is inversely proportional to the concentration and the estimated relative measurement error for concentration is $2 \%$, the relative error for pitch is less than $3 \%$. The location discrepancy between CD46 and bio-CD46 is in this error range. From the data collected for pitch (Table 1) and bandgap location (Figure 3), the refractive indices were calculated for CD46 and bio-CD46 mixtures; the results are shown in Table 2. Considering these concentrations of chiral dopant, there is no significant influence on E7 refractive indices by the chiral dopant. Fluctuations in results are due to concentration error. 


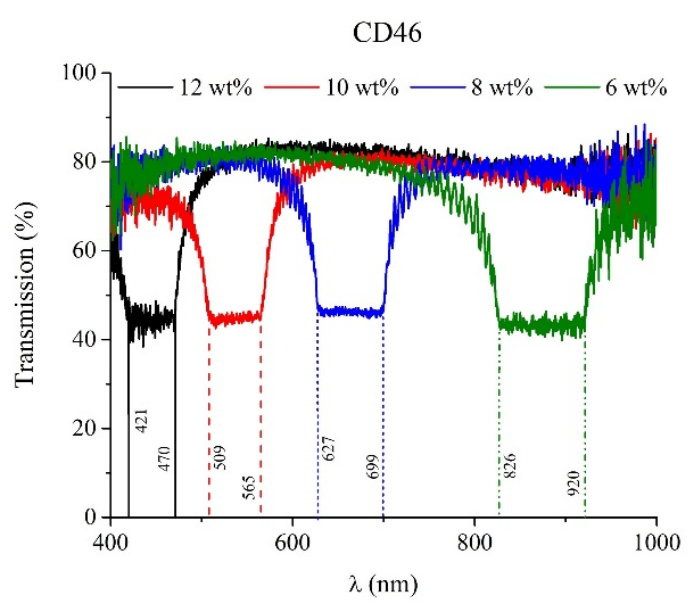

(a)

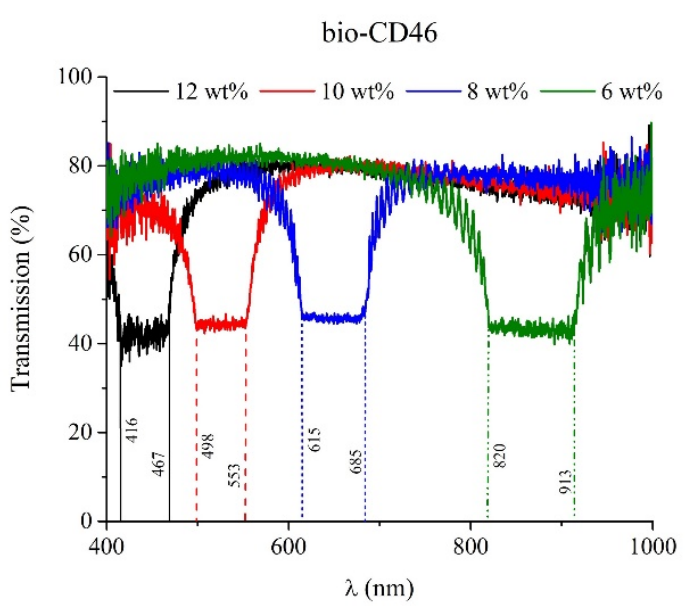

(b)

Figure 3. Transmission measurements of (a) CD46 and (b) bio-CD46 mixtures of concentrations of $12 \mathrm{wt} . \%, 10 \mathrm{wt} . \%$, $8 \mathrm{wt}$. $\%$, and 6 wt.\% in E7 showing the bandgap width location for each concentration.

Table 2. Refractive indices for different concentrations of CD46 and bio-CD46 mixtures in E7. Values were calculated using measured pitch and band edge location.

\begin{tabular}{ccccc}
\hline & \multicolumn{3}{c}{ CD46 } & \multicolumn{2}{c}{ bio-CD46 } \\
\hline $\boldsymbol{C}$ (wt.\%) & $\boldsymbol{n}_{\boldsymbol{o}}$ & $\boldsymbol{n}_{\boldsymbol{e}}$ & $\boldsymbol{n}_{\boldsymbol{o}}$ & $\boldsymbol{n}_{\boldsymbol{e}}$ \\
\hline 12 & 1.559 & 1.744 & 1.600 & 1.796 \\
10 & 1.591 & 1.766 & 1.556 & 1.728 \\
8 & 1.570 & 1.747 & 1.577 & 1.746 \\
6 & 1.558 & 1.738 & 1.547 & 1.723 \\
\hline
\end{tabular}

Selective reflection of cholesterics can be controlled by external stimulus. In order to determine the response of the reflection band to thermal and electrical stimuli, transmission spectra of cholesteric samples were analyzed. To probe the temperature dependence, a heating stage was placed in the spectrometer set up. Data was collected every $5{ }^{\circ} \mathrm{C}$ with a sweep rate of $1^{\circ} \mathrm{C} / \mathrm{min}$. To allow the system to equilibrate, the temperature sweep was paused for 5 mins prior to the acquisition of transmission spectrum. Mixtures showed weak temperature sensitivity with a very slight change in central wavelength position (Figure 4), but closer to the nematic-isotropic transition temperature, the red shift of the bandgap was observed due to cholesteric helix unwinding. To determine the reflection band response to the applied voltage, the cells with transparent ITO electrodes and $20 \mu \mathrm{m}$ gap thickness were filled with mixtures of $8 \mathrm{wt} . \%$ CD46 and bio-CD46 in E7. The transmission spectra at room temperature were obtained for several voltages at $1 \mathrm{kHz}$ applied to the cell. After every data acquisition, a $100 \mathrm{~V}$ signal was applied to align the director homeotropically. The cell was then shorted to allow relaxation to the initial state. The transmission spectra as function of applied voltage are presented in Figure 5. For voltages less than $8.3 \mathrm{~V}$, the cells show the same Grandjean textures as in the absence of an applied voltage (Figure 5-top at $0 \mathrm{~V})$. At $8.3 \mathrm{~V}$, Figure 5-top, the defect density increases slightly Figure 5-bottom. When the voltage exceeds $8.3 \mathrm{~V}$, defect lines start to grow and cause light scattering, which contributes to the decreased transmittance, Figure 5 at $9.7 \mathrm{~V}$. At $12.1 \mathrm{~V}$, a shift in the bandgap with no change in bandwidth is observed; however, the effect is small for both CD46 and bio-CD46 chiral dopants. Further increase in voltage leads to the formation of focal conic domains with a reduction in the bandwidth and decreasing transmitted intensity. At $100 \mathrm{~V}$, the cell is homeotropic and becomes fully transparent. 
CD46

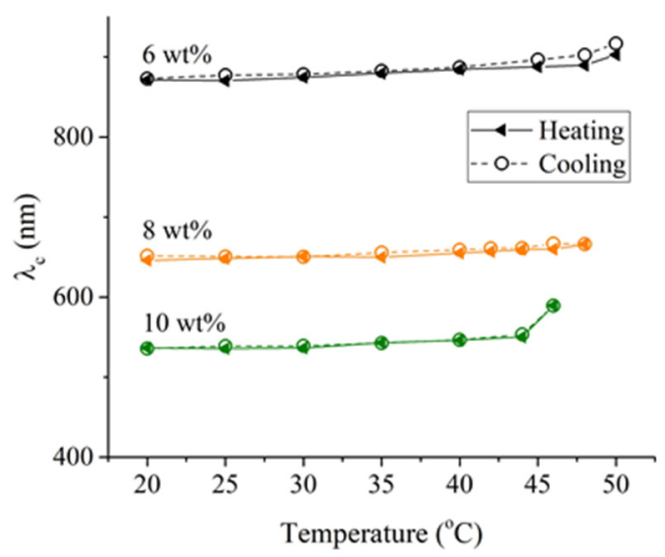

(a)

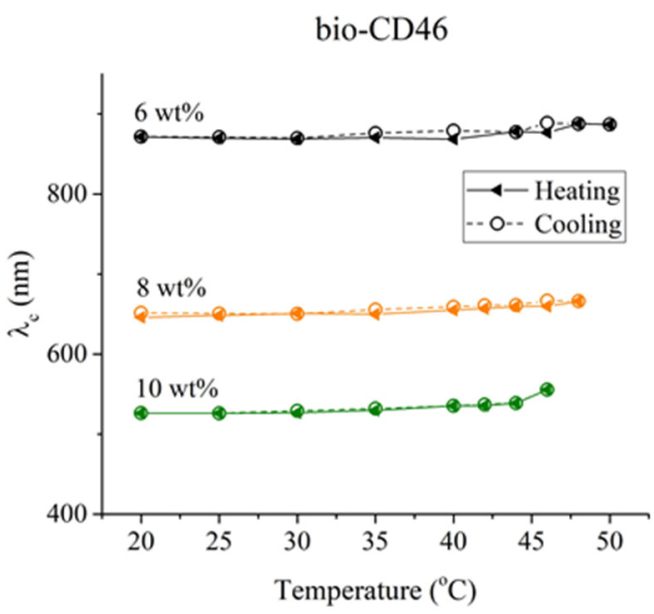

(b)

Figure 4. Temperature dependence of the reflective bandgap central wavelength $\lambda_{c}$ location for (a) CD46 and (b) bio-CD46 mixtures. Both nematic-chiral dopant mixtures showed low temperature sensitivity. Close to the nematic-isotropic transition temperature, a red shift of the bandgap is observed due to cholesteric helix unwinding.
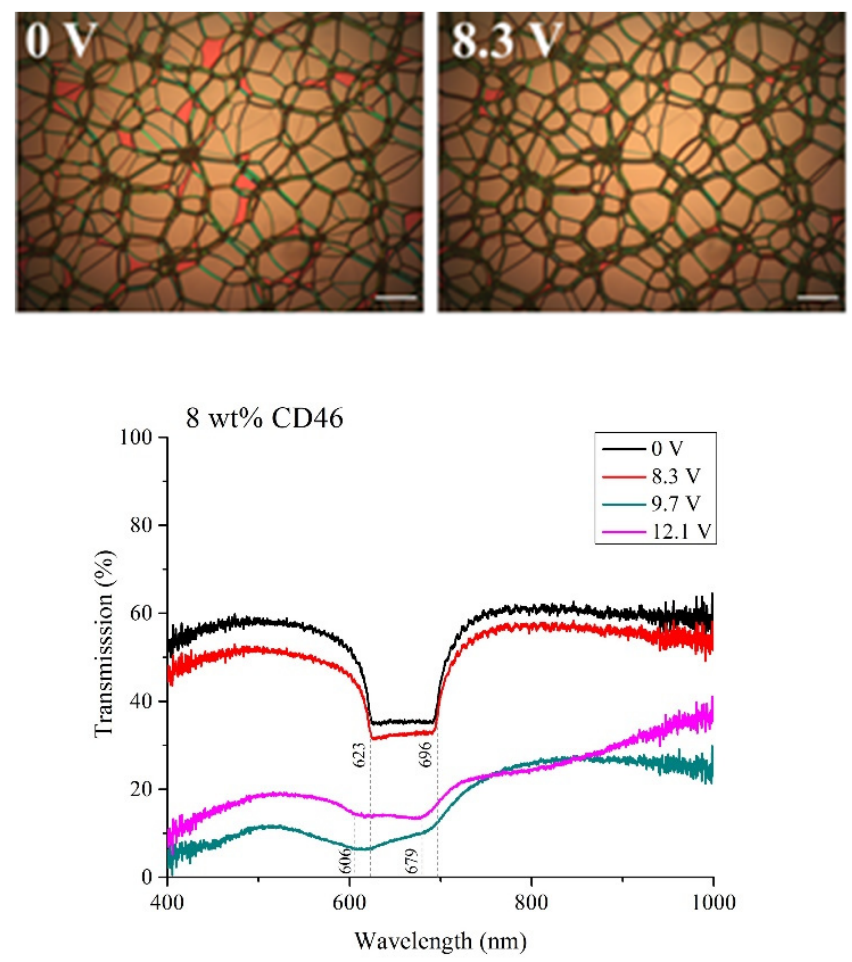
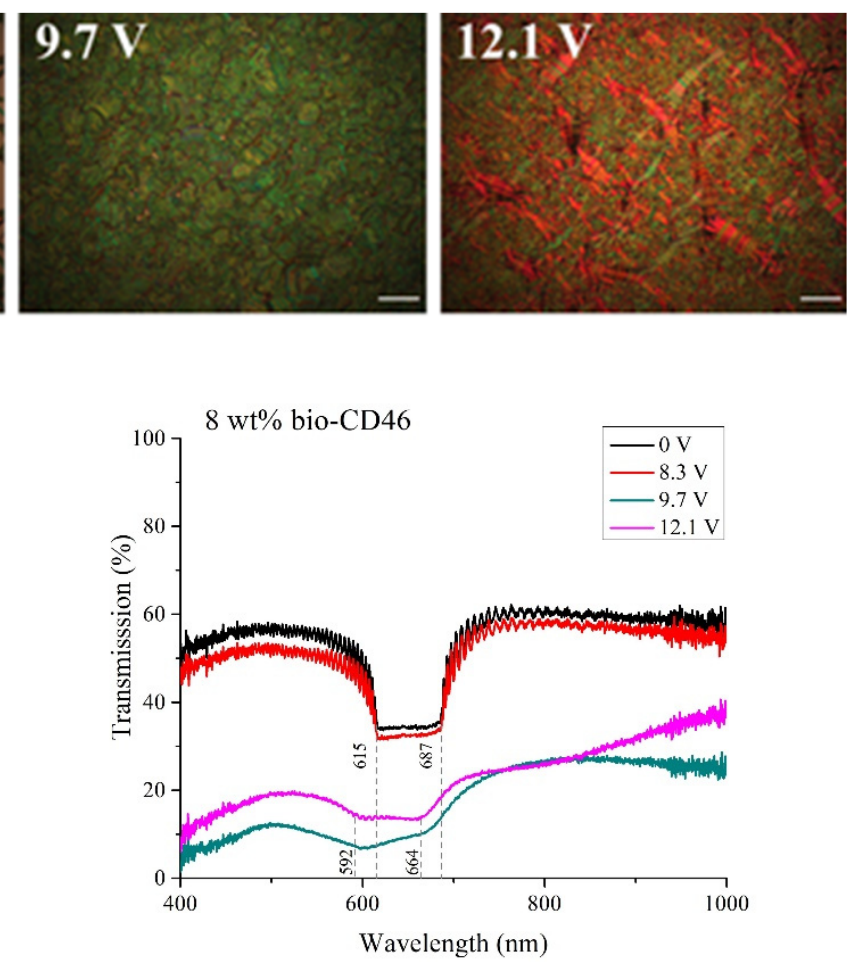

Figure 5. POM image of the texture of $8 \mathrm{wt} . \%$ bio-CD46 in E7 host depending on voltage in planar cell with $20 \mu \mathrm{m}$ gap thickness (top). Scale bar equals $100 \mu \mathrm{m}$. Transmission spectra depending on voltage for $8 \mathrm{wt} . \%$ of CD46 and bio-CD46 in E7 host (bottom).

\subsection{Stability Testing}

Structural uniformity is key to the photonic bandgap in the optical response essential for device applications. Special emphasis was placed on understanding and mitigating phase separation. In this section, results for stability testing against UV irradiation, thermal and electrical cycling, and lifetime aging are reported.

Stability testing such as UV irradiation or thermal cycling always creates many defects in the cholesteric cell. To overcome this, the task becomes decreasing the number of defects as much as possible to reduce light scattering due to defects. An effective strategy here 
is applying a high $\mathrm{AC}$ voltage to establish a homeotropic director alignment everywhere and then suddenly reducing the voltage to zero by shorting the cell. When the voltage is removed, the director assumes the helical cholesteric structure with relatively few defects. In order to determine the critical voltage required to produce the homeotropic alignment, a procedure devised was to apply an initially a small voltage, followed by $0 \mathrm{~V}$, and to measure the transmitted light through the cell between crossed polarizers. In this configuration, while the director distribution is not homeotropic, the light transmission between crossed polarizers is high, whereas the homeotropic configuration corresponds to zero transmitted intensity. The applied voltage is then gradually increased, while the intensity is monitored, the intensity remains nearly constant, until a critical voltage, above which the intensity falls to rapidly to zero. POM images for different voltages (at $1 \mathrm{kHz}$ frequency) were analyzed with ImageJ software. At each voltage, the system was equilibrated for about $10 \mathrm{~min}$. before the POM image was taken. After every acquisition, $140 \mathrm{~V}$ was applied to achieve homeotropic orientation, and the process was repeated. Transmitted intensity was measured between crossed polarizers for $6 \mathrm{wt.} \%, 8 \mathrm{wt} . \%$, and $10 \mathrm{wt} . \%$ CD46 and bio-CD46 in E7 as function of applied voltage and is presented in Figure 6. The first drop of transmitted intensity (around $10 \mathrm{~V}$ ) corresponds to changing from the Grandjean texture. At higher voltages, focal conical domains form. The second drop of intensity occurs at the critical voltage above which the cell is homeotropic. The critical voltage is highly reproducible and is a property of the sample. Here, it is used to compare commercial and bio-reachable chiral dopants.

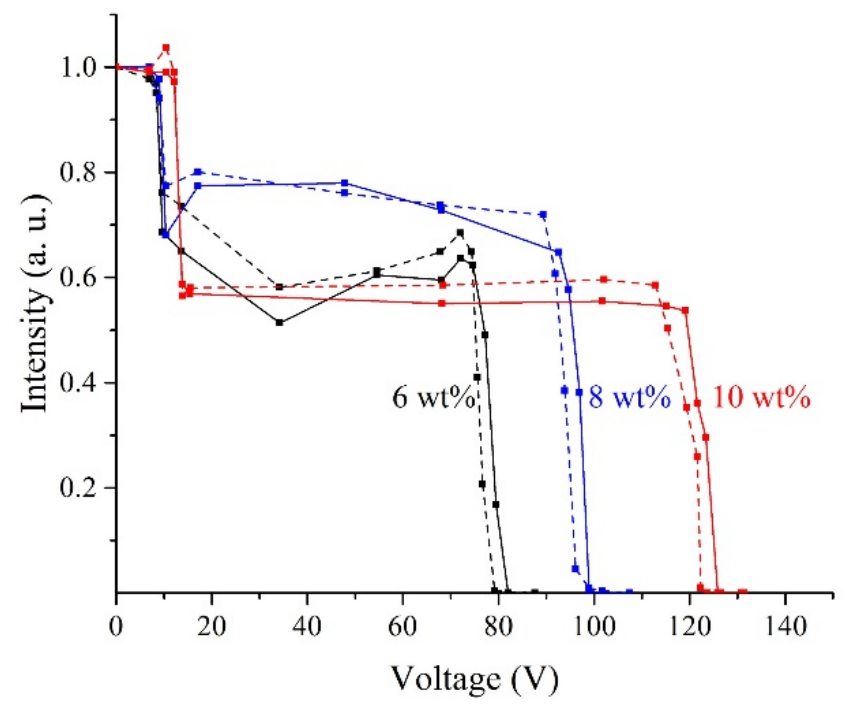

Figure 6. Transmitted light intensity vs. voltage applied to the cell for different concentrations of CD46 (dashed line) and bio-CD46 (solid line). The second drop of intensity shows the critical voltage above which the director orientation is homeotropic.

The chemical stability of the cholesteric liquid crystal under UV irradiation is a required property for a wide range of applications. UV exposure can give rise to photochemical reactions impacting the liquid crystal behavior [16]. To evaluate UV stability, a QUV tester was used, which produces light with spectrum similar to solar radiation. Stability against thermal degradation is also a key performance criterion of cholesteric bandgap materials. The thermal cycling applied in this test is standard for automotive applications, and consists of repeated 'change and hold' steps of temperature, with hold periods of 60 and $90 \mathrm{~min}$ at temperatures in the range of $-25^{\circ} \mathrm{C}$ to $+85^{\circ} \mathrm{C}$, over a $24 \mathrm{~h}$ period. Here, the stability of binary mixtures for both types of degradation were investigated utilizing transmission measurements. Transmittance is sensitive to changes in liquid crystal structure and composition, and since the reflection band for CD46 and bio-CD46 lies in the visible spectrum, it is an effective probe of stability. Results are shown in Figure 7. 
Transmission spectra were taken for mixtures with $6 \mathrm{wt} . \%, 8 \mathrm{wt} . \%$, and $10 \mathrm{wt} . \%$ of CD46 and bio-CD46 in E7 host prior to and after UV exposure for $15 \mathrm{~h}$, Figure 7-top. Transmission spectra were taken before and after thermal cycling for $24 \mathrm{~h}$, Figure 7-bottom. We note that different cells were utilized in each test. Even though a high voltage was applied to reduce defect density in the cells after UV irradiation and thermal cycling, a small difference in the transmitted intensities for the same concentrations was observed. The small deviations in band edges (about $5 \mathrm{~nm}$ ) are believed to be caused by defects. Besides the change in transmitted intensity caused by the higher defect density after each stability test, no significant evidence of any alteration of the transmission spectrum or the reflection band was observed, indicating stability of the textures against both UV and thermal degradation. The nematic host itself also exhibits UV stability [30].
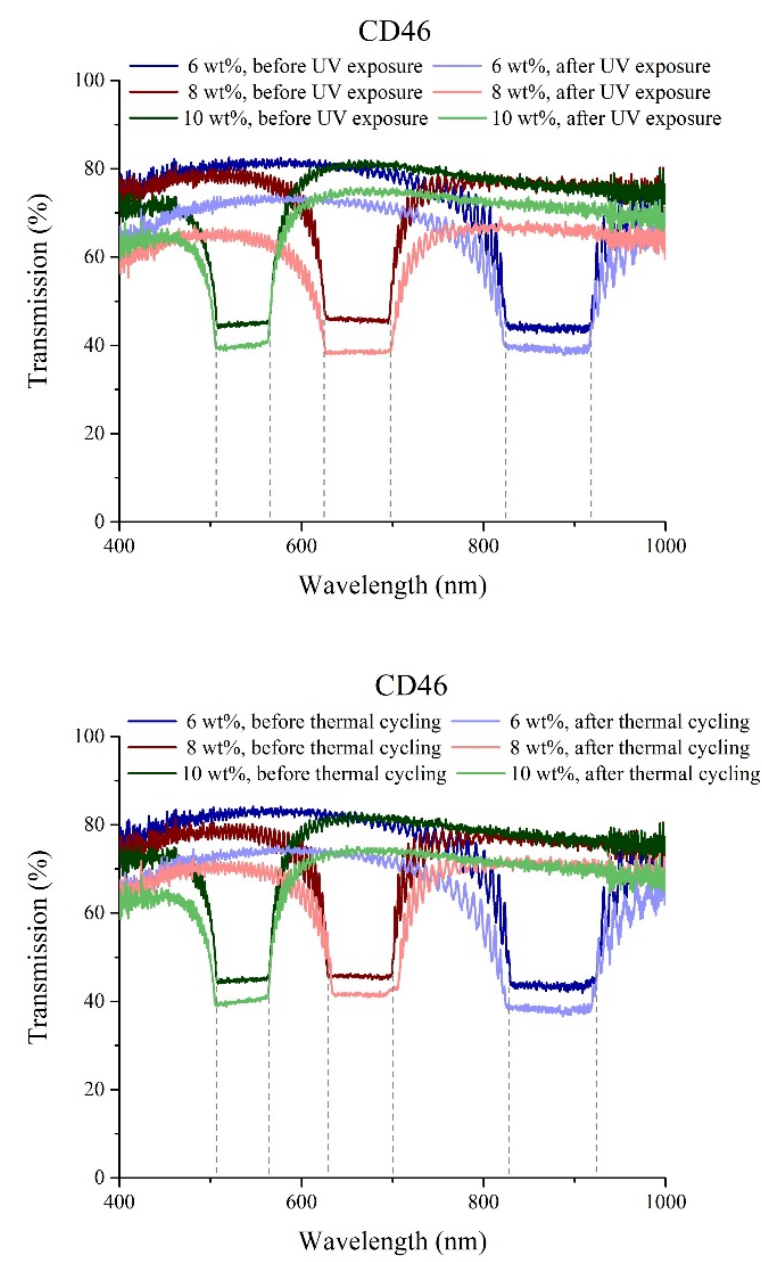
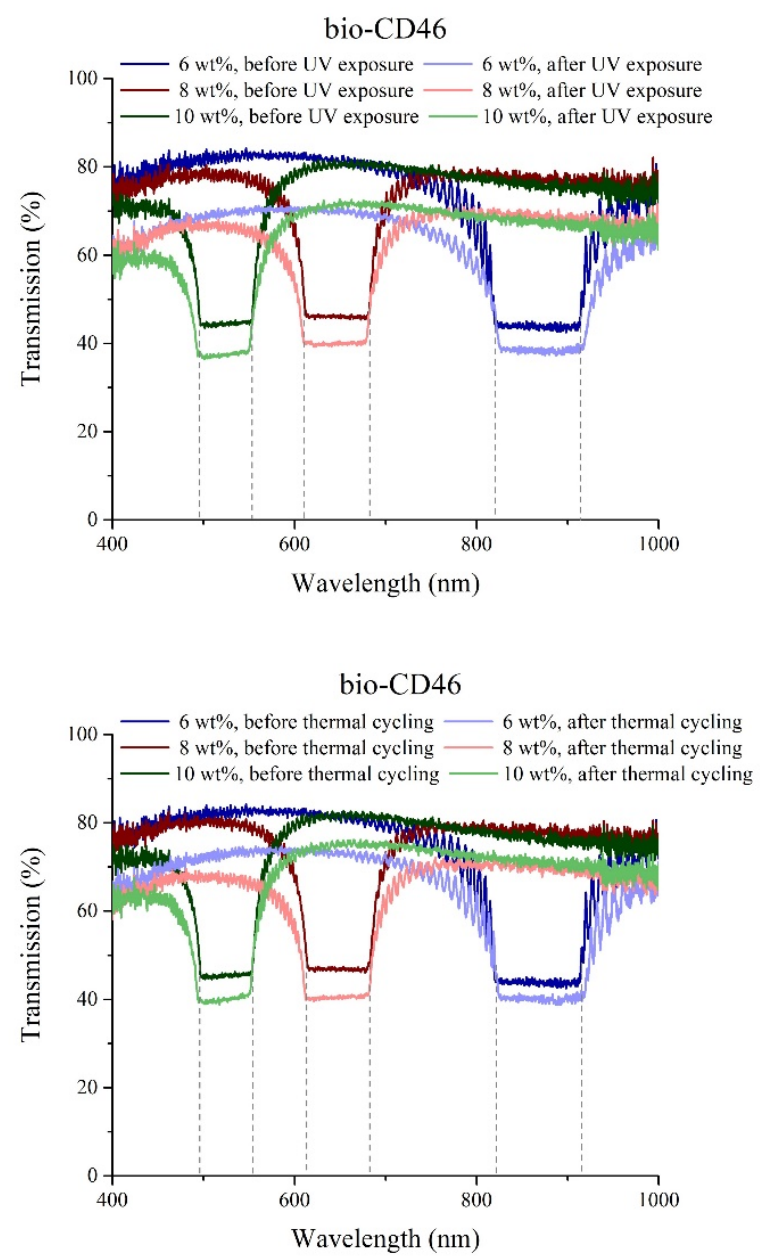

Figure 7. Transmission spectra for CD46 and bio-CD46 in E7 host (top) before and after UV exposure for $15 \mathrm{~h}$ and (bottom) before and after thermal cycling for $24 \mathrm{~h}$. There was no significant evidence of any change, indicating stability of the samples against UV and thermal degradation. Small deviations are caused by defect density.

The previously mentioned studies of physical properties required examination of cells, which had been filled and left undisturbed for extended periods of time. It was noted that certain cells had changed considerably over time. Since structural persistence is a key requirement of photonic bandgap materials in numerous applications, special emphasis was placed on understanding and mitigating the instability against phase separation. One intriguing aspect of the phase behavior of liquid crystals is the existence of long-lived metastable states [31]. It is known that the phase behavior of liquid crystals, such as crystallization and phase segregation, depends on history. The special protocol for mixture preparation was established in view of this history dependence. Furthermore, cholesteric 
mixtures show a critical chiral dopant concentration, above which phase separation eventually occurs. This critical concentration depends on the molecular structure both of the chiral dopant and of the nematic host. The stability of mixtures over time can be verified by means of transmission measurements. Figure 8 shows transmission spectra of $12 \mathrm{wt} . \%$ and $10 \mathrm{wt} . \%$ CD46 and bio-CD46 mixtures over an interval of 28 days. The slight increase in the observed transmitted intensity is believed to be due to the decrease in defect density with time. Although no appreciable wavelength shift is apparent in these measurements, a late crystallization (after six weeks) starting near the cell edges was observed. In the vials used for mixture preparation and storage, crystallization was observed in CD46 and bio-CD46 mixtures for the concentration of $12 \mathrm{wt} . \%$ within three weeks and in bio-CD29 and CD29 mixtures for above $5 \mathrm{wt} . \%$ within one week.
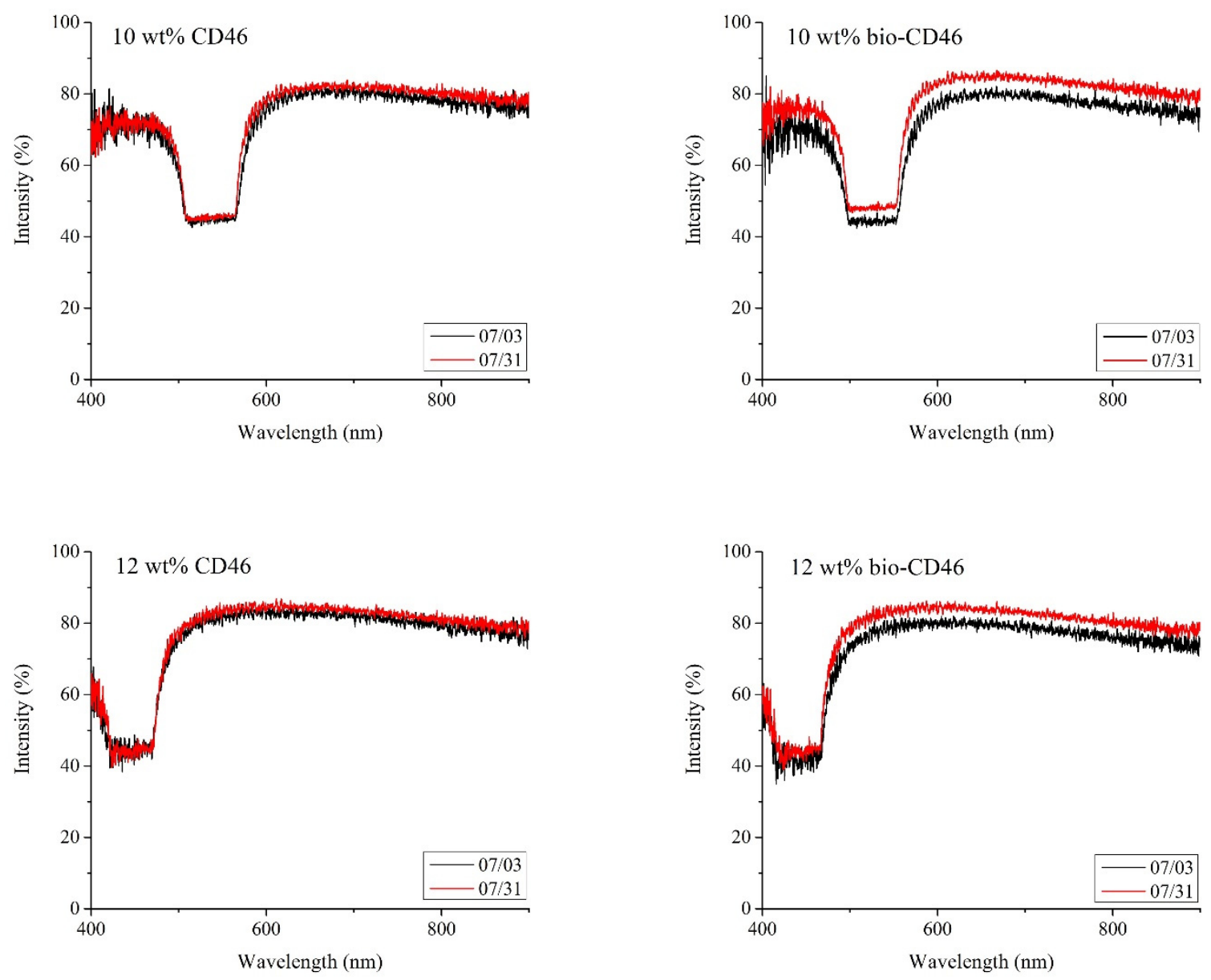

Figure 8. Transmission spectra of $12 \mathrm{wt} . \%$ and $10 \mathrm{wt} . \%$ of CD46 and bio-CD46 mixtures for an interval of 28 days. No considerable wavelength shift is observed. The slight increase in the transmitted intensity is due to the decrease in defect density with time.

When crystallization becomes a problem in binary mixtures, it may be avoided by using ternary mixtures, each with lower concentrations of the two dopants. To evaluate this strategy, several mixtures with the bio-reachable bio-CD46 and CD29 with reduced concentrations of each were prepared. This approach gives the opportunity to access a wide range of pitch with stable mixtures. The pitches of ternary mixtures were also measured using the cylindrical Grandjean-Cano wedge method. Measured values agreed well with the linear additive model [32]. Results are shown in Table 3. The concentration limit for each chiral dopant in the ternary mixtures is slightly greater than the those in the binary mixtures. For example, ternary mixtures with less than $8 \mathrm{wt} . \%$ of CD29, despite having a total chiral dopant concentration of $12 \mathrm{wt} . \%$, did not give evidence of any crystallization unlike in binary mixtures with the same concentration. Ternary mixtures also showed 
stability against UV and thermal cycling compared to chiral dopants in other binary mixtures [32].

Table 3. Pitch measurements for ternary mixtures consisting of bio-CD46 and CD29 chiral dopants in E7 nematic host. Measured pitch is compared to theoretical prediction of pitch for ternary mixtures.

\begin{tabular}{ccccc}
\hline $\mathbf{N}$ & $\begin{array}{c}\text { Mass Fraction of } \\
\text { Bio-CD46 (wt. \%) }\end{array}$ & $\begin{array}{c}\text { Mass Fraction } \\
\text { of CD29 }(\mathbf{w t} . \%)\end{array}$ & $\begin{array}{c}\text { Measured Pitch, } \\
\boldsymbol{P}(\boldsymbol{\mu} \mathbf{m})\end{array}$ & $\begin{array}{c}\text { Calculated } \\
\text { Pitch, } \boldsymbol{P}(\boldsymbol{\mu m})\end{array}$ \\
\hline 1 & 4 & 2 & 0.55 & 0.55 \\
2 & 4 & 4 & 0.42 & 0.43 \\
3 & 4 & 6 & 0.34 & 0.35 \\
4 & 5 & 5 & 0.32 & 0.34 \\
5 & 6 & 4 & 0.33 & 0.33 \\
6 & 6 & 6 & 0.28 & 0.28 \\
7 & 8 & 2 & 0.32 & 0.32 \\
8 & 8 & 4 & 0.27 & 0.28 \\
\hline
\end{tabular}

\section{Conclusions}

Two different derivatives (the bis-4-methylbenzoyl ester and the bis-4-n-butylbenzoyl ester) of betulin have been prepared and examined for use as chiral dopants in the host E7. Two esters were prepared from natural betulin (CD29 and CD46), and two esters were prepared from fermentation-derived bio-betulin (bio-CD29 and bio-CD46).

Betulin was identified as a chemical substrate, which, similar to cholesterol, could be esterified to produce chiral dopants that could be loaded into nematic hosts in sufficient quantity to produce the cholesteric liquid crystal bandgap structures, which operate in the visible and infrared range. The guest-host compositions were stable in that they did not undergo phase changes outside the desired cholesteric phase at useful loading levels. Additionally, the compositions were robust so as to have reproducible physical and optical responses to applied stimuli such as electric and magnetic fields and temperature.

Producing materials by fermentation can be an extremely attractive and cost-efficient method of producing materials, especially in large volumes.

The chemical, physical, and chirality-inducing properties of the respective pairs of natural and fermentation-derived chiral dopants were indistinguishable.

Supplementary Materials: The following are available online at https:/ /www.mdpi.com/article/10 .3390/cryst11070785/s1.

Author Contributions: All authors have contributed equally to this work. All authors have read and agreed to the published version of the manuscript.

Funding: This work was supported with funding from the Defense Advanced Research Projects Agency (DARPA) as part of the Living Foundries program, as a subcontractor of Zymergen, Inc.

Institutional Review Board Statement: Not applicable.

Informed Consent Statement: Not applicable.

Data Availability Statement: Not applicable.

Acknowledgments: We acknowledge useful discussions and guidance from Shilpa Raja, David Zalatan, and Adam Safir of Zymergen, Inc. The views, opinions, and findings presented are those of the authors and do not represent the official views or policies of the Department of Defense or the U.S. Government.

Conflicts of Interest: The authors declare no conflict of interest.

\section{References}

1. Mitov, M. Cholesteric liquid crystals in living matter. Soft Matter 2017, 13, 4176-4209. [CrossRef]

2. Reinitzer, F. Beiträge zur kenntniss des cholesterins. Mon. Chem. Verwandte Teile And. Wiss. 1888, 9, 421-441. [CrossRef] 
3. Taugerbeck, A.; Booth, C.J. Design and synthesis of chiral nematic liquid crystals discotic, biaxial and chiral nematic liquid crystals. In Handbook of Liquid Crystals; Wiley: Hoboken, NJ, USA, 2014; Volume 3.

4. Zola, R.S.; Hurley, S.; Yang, D.K. D-Limonene as a chiral dopant for thermotropic liquid crystalline systems. Appl. Phys. Express 2011, 4. [CrossRef]

5. Shin, S.; Seo, J.W.; Cho, J.K.; Kim, S.; Cha, J.; Gong, M.S. Bio-based chiral dopants having an isohexide skeleton for cholesteric liquid crystal materials. Green Chem. 2012, 14, 1163-1167. [CrossRef]

6. Xiang, J.; Varanytsia, A.; Minkowski, F.; Paterson, D.A.; Storey, J.M.D.; Imrie, C.T.; Lavrentovich, O.D.; Palffy-Muhoray, P. Electrically tunable laser based on oblique heliconical cholesteric liquid crystal. Proc. Natl. Acad. Sci. USA 2016, 113, 12925-12928. [CrossRef]

7. Amiri, S.; Dastghaib, S.; Ahmadi, M.; Mehrbod, P.; Khadem, F.; Behrouj, H.; Aghanoori, M.-R.; Machaj, F.; Ghamsari, M.; Rosik, J.; et al. Betulin and its derivatives as novel compounds with different pharmacological effects. Biotechnol. Adv. 2020, 38, 107409. [CrossRef]

8. Siman, P.; Filipova, A.; Ticha, A.; Niang, M.; Bezrouk, A.; Havelek, R. Effective method of purification of betulin from birch bark: The importance of its purity for scientific and medicinal use. PLoS ONE 2016, 11, e0154933. [CrossRef]

9. Czarnotta, E.; Dianat, M.; Korf, M.; Granica, F.; Merz, J.; Maury, J.; Baallal Jacobsen, S.A.; Forster, J.; Ebert, B.E.; Blank, L.M. Fermentation and purification strategies for the production of betulinic acid and its lupane-type precursors in Saccharomyces cerevisiae. Biotechnol. Bioeng. 2017, 114, 2528-2538. [CrossRef] [PubMed]

10. Iftime, M.M.; Marin, L. Chiral betulin-imino-chitosan hydrogels by dynamic covalent sonochemistry. Ultrason. Sonochem. 2018, 45, 238-247. [CrossRef] [PubMed]

11. Babak, N.L.; Shishkin, O.V.; Shishkina, S.V.; Gella, I.M.; Musatov, V.I.; Novikova, N.B.; Lipson, V.V. Synthesis and spatial structure of new chiral dopants from allobetuline series for cholesteric liquid-crystal compositions. Struct. Chem. 2016, 27, 295-303. [CrossRef]

12. Babak, N.L.; Semenenko, A.N.; Gella, I.M.; Musatov, V.I.; Shishkina, S.V.; Novikova, N.B.; Sofronov, D.S.; Morina, D.A.; Lipson, V.V. Synthesis of pyrrol-2-yl- and pyrazol-4-ylmethylidene derivatives of betulin and allobetulin. Russ. J. Org. Chem. 2015, 51, 715-726. [CrossRef]

13. Glushkov, V.A.; Shemyakina, D.A.; Zhukova, N.K.; Pavlogradskaya, L.V.; Dmitriev, M.V.; Eroshenko, D.V.; Galeev, A.R.; Mokrushin, I.G. Ferrocenyltriazoles from 3ß,28-Diacylbetulin: Synthesis and Cytotoxic Activity. Russ. J. Org. Chem. 2019, 55, 1690-1697. [CrossRef]

14. Castro, M.J.; Richmond, V.; Romero, C.; Maier, M.S.; Estévez-Braun, A.; Ravelo, Á.G.; Faraoni, M.B.; Murray, A.P. Preparation, anticholinesterase activity and molecular docking of new lupane derivatives. Bioorg. Med. Chem. 2014, 22, 3341-3350. [CrossRef] [PubMed]

15. Yang, D.K.; Wu, S.T. Fundamentals of liquid crystal devices. Fundam. Liq. Cryst. Devices 2014, 1-570. [CrossRef]

16. de Gennes, P.G.; Prost, J. The physics of liquid crystals. In Oxford Science Publications; Oxford University Press: New York, NY, USA, 1993; Volume 52, p. A488.

17. Li, X.; Chen, C.; Li, Y.; Jiang, X.; Li, H.; Hu, W.; He, G.; Lu, J.; Su, Y. Color holographic display based on azo-dye-doped liquid crystal. Chin. Opt. Lett. 2014, 12, 10-13. [CrossRef]

18. Yang, D.K.; Doane, J.W.; Yaniv, Z.; Glasser, J. Cholesteric reflective display: Drive scheme and contrast. Appl. Phys. Lett. 1994, 64, 1905-1907. [CrossRef]

19. Mitov, M. Cholesteric liquid crystals with a broad light reflection band. Adv. Mater. 2012, 24, 6260-6276. [CrossRef]

20. Yu, M.; Zhou, X.; Jiang, J.; Yang, H.; Yang, D.K. Matched elastic constants for a perfect helical planar state and a fast switching time in chiral nematic liquid crystals. Soft Matter 2016, 12, 4483-4488. [CrossRef]

21. Yang, Y.; Zhou, D.; Liu, X.; Liu, Y.; Liu, S.; Miao, P.-X.; Shi, Y.; Sun, W. Optical fiber sensor based on cholesteric liquid crystal film for mixed VOC sensing. Opt. Express 2020, 28, 31872-31881. [CrossRef]

22. Woliński, T.R.; Bock, W.J. Cholesteric liquid crystal sensing of high hydrostatic pressure utilizing optical fibers. Mol. Cryst. Liq. Cryst. 1991, 199, 7-17. [CrossRef]

23. Ilchishin, I.P.; Tikhonov, E.A. Dye-doped cholesteric lasers: Distributed feedback and photonic bandgap lasing models. Prog. Quantum Electron. 2015, 41, 1-22. [CrossRef]

24. Finkelmann, H.; Kim, S.T.; Muñoz, A.; Palffy-Muhoray, P.; Taheri, B. Tunable mirrorless lasing in cholesteric liquid crystalline elastomers. Adv. Mater. 2001, 13, 1069-1072. [CrossRef]

25. Muñoz, F.A.; Palffy-Muhoray, P.; Taheri, B. Ultraviolet lasing in cholesteric liquid crystals. Opt. Lett. 2001, 26, 804. [CrossRef]

26. Smith, C.R.; Sabatino, D.R.; Praisner, T.J. Temperature sensing with thermochromic liquid crystals. Exp. Fluids 2001, 30, 190-201. [CrossRef]

27. Diankov, G.; Naradikian, H.; Angelov, T. Polymer-stabilized liquid crystal indicator used in thermometry. J. Mater. Sci. Mater. Electron. 2003, 14, 831-832. [CrossRef]

28. Hanson, H.; Dekker, A.J.; Van Der Woude, F. Analysis of the pitch in binary cholesteric liquid crystal mixtures. J. Chem. Phys. 1975, 62, 1941-1946. [CrossRef] 
29. Lukishova, S.G.; Schmid, A.W.; Supranowitz, C.M.; Lippa, N.; McNamara, A.J.; Boyd, R.W.; Stroud, C.R. Dye-doped cholestericliquid-crystal room-temperature single-photon source. J. Mod. Opt. 2004, 51, 1535-1547. [CrossRef]

30. Lin, P.T.; Wu, S.T.; Chang, C.Y.; Hsu, C.S. UV stability of high birefirngence liquid crystals. Mol. Cryst. Liq. Cryst. 2004, 411, 243-253. [CrossRef]

31. Mansaré, T.; Decressain, R.; Gors, C.; Dolganov, V.K. Phase transformations and dynamics of 4-cyano-4'-pentylbiphenyl (5CB) by nuclear magnetic resonance, analysis differential scanning calorimetry, and wideangle X-ray diffraction analysis. Mol. Cryst. Liq. Cryst. Sci. Technol. Sect. A 2002, 382, 97-111. [CrossRef]

32. Liu, Y.J.; Wu, P.C.; Lee, W. Spectral variations in selective reflection in cholesteric liquid crystals containing opposite-handed chiral dopants. Mol. Cryst. Liq. Cryst. 2014, 596, 37-44. [CrossRef] 